\title{
LIBERDADE, DESENVOLVIMENTO EM JUSTIÇA NO PENSAMENTO DE AMARTYA SEN
}

FREEDOM, DEVELOPMENT AND JUSTICE IN AMARTYA SEN'S THOUGHT

\author{
${ }^{1}$ Neumalyna Lacerda Alves Dantas Marinho \\ ${ }^{2}$ Carla Danielle Barreto de Sousa Sabino
}

\section{RESUMO}

O presente artigo analisa o desenvolvimento, liberdade e justiça na concepção de Amartya Sen. Compreendendo o novo desenvolvimento como um processo que vai além do crescimento econômico, Sen ressalta a efetividade às liberdades substantivas como imprescindível à nova dinâmica desenvolvimentista. Ademais, vislumbra a privação dessas liberdades como fatores graves. No tocante aos fundamentos da justiça, Amartya Sen aponta as principais bases informacionais da justiça: o utilitarismo, o libertarismo e a justiça social de Rawls, todas com qualidades mas também limitações haja vista não levarem em consideração as liberdades substantivas. Utilizando-se o método dedutivo, a pesquisa fora qualitativa e bibliográfica.

PALAVRAS-CHAVE: Liberdade; Desenvolvimento; Justiça; Amartya Sen

\begin{abstract}
This article analyzes the development, justice and freedom in the design of Amartya Sen. Understanding the new development as a process that goes beyond economic growth, Sen emphasizes the effect to substantive freedoms as essential to the new developmental dynamics. Moreover, envisions the withdrawal of these freedoms as major factors. As regards the foundations of justice, Amartya Sen points out the main informational basis of justice: utilitarianism, libertarianism and social justice Rawls, all with qualities but also limitations considering not taking into account the substantive freedoms. Using the deductive method, search out qualitative and literature.
\end{abstract}

KEYWORDS: Freedom; Development; Justice; Amartya Sem

\footnotetext{
${ }^{1}$ Graduada em Direito pela Universidade Federal de Campina Grande. Especialista em Direito Administrativo e Gestão Pública. Mestranda em Direito, Desenvolvimento e Sustentabilidade pelo Centro Universitário de João Pessoa - UNIPÊ, João Pessoa, Paraíba, PB, (Brasil). E-mail:

${ }^{2}$ Graduada em Direto pelo Centro Universitário de João Pessoa. Especialista em Direito Público pela Faculdade AmbecTrabuco. Mestranda em Direito, Desenvolvimento e Sustentabilidade pelo Centro Universitário de João Pessoa - UNIPÊ, João Pessoa, Paraíba, PB, (Brasil ). E-mail: carladaniellebss@gmail.com.
} 


\section{INTRODUÇÃO}

O presente artigo tem por objetivo trabalhar a perspectiva de liberdade, desenvolvimento e justiça na concepção de Amartya Sen, indiano e economista que se destacou no campo da teoria política, recebeu o prêmio Nobel de Economia, foi um dos pensadores e idealizadores do Índice de Desenvolvimento Humano-IDH, professor na Universidade de Harvard e grande estudioso do processo de desenvolvimento, não apenas na perspectiva de crescimento econômico, mas também das liberdades substantivas e capacidades dos indivíduos de terem uma vida de qualidade.

Amartya Sen aponta como novo desenvolvimento, concomitantemente ao crescimento econômico e aferição de renda, a qualidade de vida e liberdade do indivíduo para fazer o que deseja. Eleva a qualidade de vida das pessoas à fator de influência e intervenção no mundo que se anseia desenvolvido.

Como mitigadores do processo de desenvolvimento pleno e verdadeiro, Sen elenca formas de privação de liberdades, dentre elas a fome coletiva, a negação de direitos políticos, os ineficientes e insatisfatórios serviços de saúde, educação, saneamento, as diferenças de gênero no tocante aos direitos e oportunidades sociais, a não participação na vida política e a falta dos direitos civis a prejudicar de forma veemente o exercício pleno da cidadania e quisá da democracia.

Diferencia-se os fenômenos do desenvolvimento e da modernização, sendo trazida a pesquisa a análise de Amartya Sen no tocante aos países extremamente modernos em seus centros de poder e contraditoriamente possuidores, em suas periferias, de elevadas taxas de pobreza e mal estruturação, não havendo como tais países serem considerados desenvolvidos.

Finalmente, trata a pesquisa dos fundamentos da justiça, abordando-se três bases informacionais, quais sejam, o utilitarismo clássico e moderno, o libertarismo e a justiça social de John Rawls, esta última indicada por Amartya Sen como uma das mais influentes das teorias contemporâneas de justiça. Observa-se, consoante ensinamentos de Amartya Sen, que todas essas bases informacionais são importantes e possuem seus benefícios, porém finalizam em uma limitação, qual seja, a de não levarem em consideração as liberdades substantivas.

O presente estudo, utilizando-se do método dedutivo, consoante os ensinamentos de Amartya Sem no sentido de desenvolvimento pleno abrangendo além do crescimento 
econômico de um Estado corresponde a efetividade das liberdades substantivas da sociedade, traz uma pesquisa, do ponto de vista dos conhecimentos técnicos, bibliográfica, elaborada a partir das leituras das obras de Amartya Sem assim como de outros eminentes estudiosos da temática de desenvolvimento, liberdade e teorias da justiça. Do ponto de vista da abordagem ao problema, a pesquisa é qualitativa no sentido de que compreende o desenvolvimento como fenômeno não quantitativo e portanto traduzido meramente em números e sim como um fenômeno que, além de preocupar-se com o crescimento econômico, reconhece a fundamentalidade da qualidade de vida e liberdade substantiva da sociedade.

\section{LIBERDADE COMO CAPACIDADE}

As inquietações sobre a relação entre direito e desenvolvimento são inúmeras, sendo vários os autores, economistas e juristas, a tentar explicar, de forma sistemática, a evolução dessa intrínseca relação. Amartya Sen foi um grande protagonista nesta área, considerando as liberdades, as quais denomina liberdades substantivas, como a capacidade de o indivíduo satisfazer seus anseios e necessidades sem interferências oportunistas e canalizadas a interesses outros que não seja primordialmente a qualidade de vida do ser humano envolto em um processo de desenvolvimento pleno.

O indiano Amartya Sen, de forma crucial, discute e resgata as relações entre rendas e a satisfação da pessoa enquanto indivíduo inserido no seio da sociedade, dinâmica das mercadorias e capacidades, sendo enfatizado, como elemento integrante do desenvolvimento, a possibilidade destes indivíduos viverem da forma que gostariam a resultar nas chamadas liberdades substantivas. Sen (2015, p.28) muito bem esclarece:

A utilidade da riqueza está nas coisas que ela pode nos permitir fazer-as liberdades substantivas que ela nos ajuda a obter. Mas essa relação não é exclusiva (porque existem outras influências significativas em nossa vida, além da riqueza) nem uniforme (pois o impacto da riqueza em nossa vida varia conforme outras influências). (...) Uma concepção adequada de desenvolvimento deve ir muito além da acumulação de riqueza e do crescimento do Produto Nacional Bruto e de outras variáveis relacionadas à renda.

Alocando o indivíduo como o sujeito principal no processo de desenvolvimento, capacitado a interagir, conforme sua satisfação, e influenciar o mundo em que vive, Amartya 
Sen coloca ao lado do crescimento econômico, as liberdades substantivas como elementos indispensáveis na configuração do verdadeiro e pleno desenvolvimento.

Nessa senda de desenvolvimento pleno também são as alusões de Rivero (2002, p.132):

São gurus do mito do desenvolvimento que têm uma visão quantitativa do mundo. Ignoram os processos qualitativos histórico-culturais, o progresso não linear, as abordagens éticas, e até prescindem dos impactos ecológicos. Confundem crescimento econômico com o desenvolvimento de uma modernidade capitalista que não existe nos países pobres.

De nada adianta a existência de Nações com grande crescimento econômico, integradas por uma sociedade/ indivíduo que sofrem fortes formas de privação da liberdade. Amartya Sen descreve algumas formas de privação da liberdade modicamente tratadas nesta pesquisa.

Uma das mais antigas e concomitantemente atuais formas de restrições das liberdades são as fomes coletivas a configurar a situação onde milhares de pessoas não possuem a "liberdade básica" de viver, alimentar-se corretamente e ou tão somente alimentar-se. Milhares de pessoas não possuem as condições mínimas de sobrevivência, quisá de uma vida digna.

Outra forma de privação de liberdade analisada por Amartya Sem é o minguado acesso aos serviços de saúde, saneamento básico, educação, segurança pública, emprego digno e remunerado dispostos à população. Vislumbra-se a ineficiência desses imprescindíveis serviços em muitas Nações que antagonicamente possuem cidades intensamente modernas e em contrapartida outras extremamente mal estruturadas onde às pessoas é negado serviços mínimos à uma vida saudável e digna, a estas é, inescrupulosamente, castrado seu poder de escolha e de capacidade a serem oportunizados obrigatoriamente pelo Estado, em uma nítida configuração de desenvolvimento falsiado, crescimento econômico, tão somente, desatrelado de estruturação social. Mesmo nos países economicamente mais ricos é muito comum haver pessoas imensamente desfavorecidas, carentes de oportunidades básicas de acesso a serviços de saúde, educação funcional, emprego remunerado ou segurança econômica e social. (SEN, 2015, p.29).

Em consonância à Amartya Sen, quando da compreensão do desenvolvimento sob os aspectos econômicos e concomitantemente sociais, Bercovicci (2005, p.53):

Quando não ocorre nenhuma transformação, seja social, seja no sistema produtivo, não se está diante de um processo de desenvolvimento, mas de 
modernização, mantendo o subdesenvolvimento, agravando a concentração de renda.

O referido autor aborda a questão da modernidade como fenômeno diverso do desenvolvimento e também nesse aspecto seus ensinamentos coadunam-se aos de Amartya Sen.

Continuando o rol elencado por Amartya Sen das diversas formas de restrição da liberdade está a negação aos direitos e liberdade políticas e civis; restrição essa que, além de enfraquecer a economia, está atrelada à desconsideração da democracia, a mitigar consideravelmente o pleno desenvolvimento dos Estados e, por sua vez, influenciar negativamente os altos índices de pobreza vivenciados por muitos países no globo, autoritariamente governados.

Incisivo coloca-se Sen (2015, p. 31) quando da importância dos direitos e liberdades políticas e civis: "As liberdades políticas e civis são elementos constitutivos da liberdade humana, sua negação, em si, é uma deficiência”. Ademais, ainda Sen $(2015$, p.30) atrela aos direitos e liberdades políticas e civis a função de impedir a ocorrência de outras restrições às liberdades substantivas, a exemplo da fome coletiva, senão vejamos: "O funcionamento da democracia e dos direitos políticos pode até mesmo ajudar a impedir a ocorrência de fomes coletivas e outros desastres econômicos".

A desigualdade de gênero entre o sexo feminino e masculino é elencada como outro fator maculador das liberdades substantivas. Vislumbrada diuturnamente nos mais diversos setores sociais, a exemplo do setor laboral, a restrição da liberdade e dos direitos das mulheres tem-lhes privado a oportunidade equânime de capacitação e, por conseguinte, interferido negativamente no processo de desenvolvimento pleno dos Estados, integrados por homens e mulheres igualitariamente essenciais à dinâmica econômica, social e cultural de uma sociedade.

Pormenorizando suas alegações à questão das diferenças de gênero como fenômeno mitigador das liberdades e direitos civis notadamente das mulheres, pronuncia-se Veiga (2010, p.55): "não é de se admirar, por exemplo que sociedades machistas, que oprimem as mulheres e desdenham de seu trabalho, tenham economias lamentavelmente fracas".

Finalmente, sem qualquer pretensão de esgotar as hipóteses mitigadoras das liberdades substantivas apregoadas por Amartya Sem, aborda-se o minguado e ineficiente sistema de saúde, educação e saneamento básico ofertado pelo Estado, como incapaz de oportunizar uma vida digna aos indivíduos. Sem serviços de saúde de qualidade, saneamento básico eficaz e educação capacitante não há como o indivíduo desenvolver-se e despontar-se capaz e 
saudavelmente operante na dinâmica social desenvolvimentista. Sem serviços de saúde, de saneamento e educacional de qualidade aos indivíduos resta a posição de eternos dependentes da atitude caridosa do Estado, postura esta antagônica a uma projeção desenvolvimentista plena, a envolver questões socais, econômicas e culturais.

Referindo-se ás formas de restrições de liberdade de uma forma geral, Sen (2015, p.32) defende que para ocorrer verdadeiramente a liberdade é necessário a concretização dos processos e oportunidades. "A visão de liberdade envolve tanto os processos que permitem a liberdade de ações e decisões como as oportunidades reais que as pessoas têm, dadas as suas circunstâncias pessoais e sociais." Continua, apregoando que processos errôneos ocasionam a não oportunidade e a não possibilidade de escolha pelas pessoas de realizar o que necessitam e desejam. Urge a afirmação de processos a proporcionar e permitir a liberdade dos indivíduos; cada um com suas peculiaridades a desenvolver suas capacidades e tomar suas decisões, conforme seus anseios e necessidades.

Na senda das alegações de Sen, Veiga (2010, p.85) aduz que o objetivo básico do desenvolvimento é no sentido de alargar as liberdades humanas; apenas assim as pessoas interferirão nas decisões capazes de afetar suas vidas e garantir seus direitos. Continua Veiga (2010, p. 85): “A gama de capacidades que os indivíduos podem ter e as escolhas que podem ajudar a expandir essas capacidades são potencialmente infinitas, embora variem muito conforme a pessoa".

A restrição das liberdades substantivas, como elemento relevantemente negativo na mitigação do processo de desenvolvimento pleno, ocasiona a pobreza, que não se resume à falta ou insuficiência de dinheiro, atrelada ademais à deficiência de saúde, educação, valores cívicos, trabalho digno, à desigualdade de gênero e à restrição dos direitos políticos e civis, elementos estes últimos sine qua non à afirmação da democracia.

A pobreza, em sentido estrito, é uma forma de privação básica da liberdade de viver com dignidade, ocasionando, como aponta Sen (2015), morte prematura, desnutrição, analfabetismo, falta de oportunidade de capacitação a comprometer, por conseguinte, a sobrevivência do indivíduo na dinâmica social. Vislumbrada não apenas em Nações economicamente subdesenvolvidas, a pobreza é fenômeno encontrado em Estados considerados ricos. Sen (2015, p.38) demonstra em suas pesquisas que o nível de pobreza e mortalidade da 
periferia ou de grupos específicos dos países muito ricos equivalem às Nações de Terceiro Mundo. ${ }^{3}$

A pobreza é em muito ocasionada pelos altos níveis de desemprego a influenciar negativa e consideravelmente a exclusão social daqueles que sem oportunidades de capacitação, não são integrados como iguais em direitos e obrigações na sociedade, sendo-lhes mitigado seu status de cidadão e a dignidade de vida inerente a todo ser humano.

Respondendo a questão de como proporcionar à sociedade as oportunidades imprescindíveis ao desenvolvimento pleno, Sen (2015) afirma que a expansão das capacidades das pessoas de levar a vida que desejam podem ser aumentadas através das políticas públicas. Estas, segundo Sen, são os meios que o Estado detém para efetivação dos direitos, das liberdades e capacidades da sociedade/indivíduo.

Em alusão às políticas públicas como instrumentos para a efetivação das liberdades substanciais, capacitação das pessoas e garantia de direitos, Bercovici (2005, p.62 e 63) aduz não ser este o único meio hábil a ser utilizado pelo Estado para o desenvolvimento: “(...) não é possível promover ou compreender o papel do Estado no desenvolvimento exclusivamente pelas políticas públicas. As políticas públicas são sempre programas setoriais”.

Consoante o exposto nos ensinamentos de Sen é possível a compreensão do desenvolvimento como um complexo processo que envolve, além da consecução de rendas, a afirmação das liberdades substantivas e das capacidades; estas últimas a intervir na qualidade devida dos indivíduos e no modelo social instaurado. A liberdade, ao influenciar na qualidade de vida das pessoas não deixa de ser uma forma de riqueza.

Abordaremos, no tópico seguinte com mais nuances as questões próprias do novo e verdadeiro desenvolvimento, realizando a interligação com a liberdade lançada por Amartya Sen, para ele "desenvolvimento como liberdade".

\section{NOVO DESENVOLVIMENTO}

Diante das perspectivas impostas há de se discutir e pesquisar sobre os aspectos e as características do novo desenvolvimento. Chama-se aqui de novo desenvolvimento, devido a nova formulação e conceituação aplicada pelos atuais pesquisadores do tema, diversamente

\footnotetext{
${ }^{3}$ Atualmente, a expressão "Terceiro Mundo" está obsoleta. Porém, será usada no texto do presente artigo, para indicar os países "subdesenvolvidos", tidos como aqueles que estão em processo de desenvolvimento ou almejam alcançá-lo.
}

Revista de Teorias da Justiça, da Decisão e da Argumentação Jurídical e-SSN: 2525-9644|Curitiba|v.2|n. 2|p.101-116| Jul/Dez. 2016. 
construída do que se aplicava anteriormente, onde desenvolvimento era sinônimo de crescimento econômico.

Como bem assevera Veiga (2010, p.17):

A mais frequente é tratar o desenvolvimento como crescimento econômico. Isto simplifica a tarefa de responder à pergunta, pois dois séculos de pesquisas históricas, teóricas e empíricas sobre o crescimento econômico reduziram bastante a margem de dúvida sobre esta noção (...).

Sen (2015) explica que há dois lados do desenvolvimento, aquele que remete ao acúmulo de riqueza, crescimento econômico e o outro que comporta e prioriza as causas sociais, a liberdade política, a garantia dos direitos civis e as liberdades substantivas, este último é o aspecto priorizado e desenvolvido no presente artigo.

Duas vertentes são impostas para se atingir o desenvolvimento, alguns defendem que para alcançá-lo deve-se inicialmente estimular e proporcionar o enriquecimento do país e nesta perspectiva, em uma nítida restrição aos princípios democráticos, o mais apropriado e aconselhável seria reduzir drasticamente os serviços sociais, os gastos com as políticas públicas e segurança pública. Para esta vertente, primeiro a preocupação volta-se ao crescimento econômico, aos índices da economia e só posteriormente os esforços voltar-se-ão aos índices de desenvolvimento humano e consequente investimento nos setores sociais de políticas públicas de saúde, educação, segurança e etc. Muito própria a esta vertente o jargão popular "Inicialmente o bolo tem que crescer para depois reparti-lo".

Vivencia-se na conjuntura política, social e econômica da República Federativa do Brasil um estado de recessão, uma nação preocupada em reestabelecer a economia e para isso pratica ações de cortes sociais em vários setores, tais quais: segurança pública, saúde, educação básica e superior, além de um processo político precário e vicioso. Sachs (2007, p. 292 e 293) aponta que o Brasil representa um caso típico de mau desenvolvimento e a democracia brasileira ainda não se libertou das práticas clientelistas, das tentativas repetidas de privatização do estado e da corrupção. Os benefícios do crescimento e da modernização econômicos são confiscados por uma elite estreita.

A outra vertente do desenvolvimento, acatada por vários pesquisadores, a exemplo de Sen (2015, p.55), é aquela que caminha lado a lado com a perspectiva social, considerando as liberdades substantivas e as capacidades dos indivíduos como elementos sine qua non no processo do verdadeiro desenvolvimento. 
Liberdades substantivas incluem capacidades elementares como, por exemplo, ter condições de evitar privações como a fome, a subnutrição, a morbidez evitável e a morte prematura, bem como as liberdades associadas a saber ler e escrever, fazer contas, ter participação política.

Coadunando com os ensinamentos de Sen, Veiga (2010) aduz que "desenvolvimento" não é sinônimo de crescimento econômico, nem tampouco um mito ou ilusão, ele é o "caminho do meio". O desenvolvimento não pode ser analisado apenas pelo Produto Interno Bruto - PIB ou renda, tem que existir concomitante a este o cuidado aos setores sociais.

$\mathrm{Na}$ demonstração desse "caminho do meio", expressão apregoada por Veiga (2010) faz-se necessário realizar uma breve retrospectiva do que antes caracterizava o desenvolvimento. Até pouco tempo atrás falar em desenvolvimento, necessariamente era limitá-lo ao crescimento econômico, isto significa dizer que os países ricos, com uma forte economia, eram desenvolvidos ao contrário daqueles "pobres" em acúmulo de rendas. Vejamos o que leciona Veiga (2010, p.18):

Até o início dos anos 1960, não se sentiu muito a necessidade de distinguir desenvolvimento econômico de crescimento econômico, pois as poucas nações desenvolvidas eram as que se haviam tornado ricas pela industrialização. De outro lado, os países que haviam permanecido subdesenvolvidos eram os pobres, nos quais o processo de industrialização era incipiente ou nem havia começado.

Contudo, quando essas nações "pobres" obtiveram um forte crescimento econômico em virtude da industrialização, elas não conseguiram expandir o crescimento em todos os aspectos, isto é, não oportunizaram à sociedade acesso à saúde pública satisfatória e eficiente, educação básica de qualidade, não aumentaram os níveis de alfabetismo e ou o trabalho digno e remunerado. O termo desenvolvimento arraigado, tão somente, ao acúmulo de riquezas e crescimento econômico restou obsoleto. $\mathrm{O}$ desenvolvimento deixou de ser medido por índices de aferição de renda apenas, sendo incluído o Índice de Desenvolvimento Humano (IDH) como parâmetro concomitante a sua promoção e configuração.

Sen (2015, p.55) estabelece: "é importante ver o desenvolvimento como um processo de expansão das liberdades reais que as pessoas desfrutam, e essa expansão é considerada um fim primordial e o principal meio do desenvolvimento". Este renomado estudioso elenca cinco liberdades instrumentais como meio para alcançar o pleno desenvolvimento. As liberdades políticas, interligadas aos direitos políticos a significar a capacidade de escolher quem deve governar, o direito de votar e ser votado, possuir liberdade de expressão e fiscalização dos atos 
políticos; como segunda liberdade instrumental as facilidades econômicas relacionadas com as rendas aferidas, o poder de consumo, produção e troca, no sentido de que o crescimento econômico do país necessariamente ocasionará reflexos na riqueza da população. A terceira liberdade elencada por Sen diz respeito às oportunidades sociais ofertadas para a sociedade viver melhor, a exemplo das políticas de saúde pública, educação de qualidade, segurança pública, saneamento básico, afastabilidade da miséria e fome. (SEN, 2015, p.59). Como quarta como meio de desenvolvimento tem-se a garantia de transparência, figurando como forte arma no combate da corrupção e como quinta e última forma de liberdade tem-se a segurança protetora a servir de alicerce para a a segurança social (SEN, 2015, p.60).

No intuito da concretização do pleno e verdadeiro desenvolvimento devem as nações propiciar a afirmação das liberdades instrumentais, elencadas e defendidas por Amartya Sem. Além da preocupação com a produção e acúmulo de riquezas a elevar os índices econômicos, devem os Estados dispendiar esforços para efetivar a liberdade das pessoas em suas escolhas, oportunizar a expansão e valorização de suas capacidades na medida de suas peculiaridades individuais além de garantir seus direitos. Nesse sentido esclarece Veiga (2010, p.85):

A gama de capacidades que os indivíduos podem ter e as escolhas que podem ajudar a expandir essas capacidades são potencialmente infinitas, embora variem muito conforme a pessoa. Porém a política pública trata de fixar prioridades, e há dois critérios úteis na identificação das capacidades (...) essas capacidades devem ser valorizadas. (...) devem ser básicas para a vida, no sentido de que sua ausência impediria muitas outras escolhas.

$\mathrm{O}$ crescimento se transforma em desenvolvimento quando se preocupa com a qualidade de vida das pessoas no seio da sociedade, não é riqueza em quantidade, mas qualidade de vida, riqueza em qualidade. Furtado (2000, p.8) aduz que: “O desenvolvimento deve ser entendido como processo de transformação da sociedade não só em relação aos meios, mas também aos fins, o homem como agente transformador do mundo". A sociedade não como objeto do desenvolvimento e sim como o sujeito desse desenvolvimento.

Ante esta concepção vislumbra-se que o crescimento, tão somente, da economia está aquém para refletir o processo de real desenvolvimento, processo de desenvolvimento este que há de ser construído em uma perspectiva não apenas econômica, mas também de parâmetros sociais. Há a necessidade, na efetivação do pleno e verdadeiro desenvolvimento, da promoção das liberdades, e extirpação de tudo que venha a privá-las e ou restringí-las, nesse sentido a liberdade de não passar fome, de saber contar e escrever, entre outras. Bercovici (2005, p.51) 
reforça: "o mercado não pode ser condutor do desenvolvimento, e este desenvolvimento é condição necessária para a realização do bem-estar”.

Outro fator preponderante e necessário que se demonstre é a diferenciação entre desenvolvimento e modernização. Muitas vezes confundidos e aplicados como sinônimos, desenvolvimento não significa modernização. Vislumbra-se com frequência países/nações com cidades em alto grau de modernização, porém não tão desenvolvidos.

Para atingir o desenvolvimento, necessariamente não se exige que a nação tenha que passar pelo estágio do subdesenvolvimento, este não é uma fase necessária. " $\mathrm{O}$ subdesenvolvimento é portanto um processo histórico autônomo e não uma etapa pela qual tenham, necessariamente, passado as economias que já alcançaram grau superior de desenvolvimento" (FURTADO, 2000, p.197). Para ocorrer o desenvolvimento é necessário que se alcance a promoção econômica, produtiva e social, não havendo essa transformação/promoção social, não se estará diante do desenvolvimento, mas sim da modernização.

Bercovici (2005, p. 53) afirma que "crescimento sem desenvolvimento é aquele que ocorre com a modernização, sem qualquer transformação nas estruturas econômicas e sociais". Em uma grande maioria vislumbramos cidades muito modernas, porém sua periferia está acometida de falta de saneamento básico, coleta de lixo, não possui educação básica de qualidade e saúde pública precária, além de falta de empregos formais, culminando com a falta de dignidade. Comparato (1999, p.410) ressalta que o desenvolvimento econômico e social, com a eliminação das desigualdades pode ser considerado como a síntese dos objetivos históricos nacionais.

Portanto, resta muito bem compreendido o novo desenvolvimento, desvencilhado da ideia única e exclusiva de crescimento econômico, indo além disto, englobando as liberdades públicas e oportunidades de capacitação a influenciar a qualidade de vida dos indivíduos, como bem ilustra Veiga (2010, p.56): "crescimento é um fator muito importante para o desenvolvimento. Mas não se deve esquecer que no crescimento a mudança é quantitativa, enquanto no desenvolvimento ela é qualitativa".

No alcance do desenvolvimento pleno e verdadeiro, além do crescimento econômico, há de haver o fortalecimento dos projetos sociais, a rigidez das democracias fragilizadas, a proteção dos direitos humanos assim como a efetivação e não privação das liberdades substantivas. 


\section{FUNDAMENTOS DA JUSTIÇA}

Amartya Sen na sua perspectiva de justiça trata de três bases informacionais: o utilitarismo, o libertarismo e a teoria da justiça de Rawls, destacando as falhas de cada uma. Discutiremos no presente tópico esses fundamentos de justiça no pensamento de Sen e sua abordagem alternativa baseada na liberdade dos indivíduos.

Para Sen (2015, p.80 e 81) o que caracteriza um abordagem avaliativa são as informações necessárias, usadas no poder decisório assim como as informações excluídas que não podem ter influência no poder avaliatório.

Inicialmente cabe retratar um pouco sobre os princípios utilitaristas, onde Sen (2015, p.81 e 82) divide em utilitarismo clássico e utilitarismo moderno. No utilitarismo clássico, de Bentham, a utilidade é conceituada como felicidade, prazer, satisfação. Não possui interesse na distribuição pois, a concentração se dá na utilidade total de todos os indivíduos, considerados um conjunto. Já no utilitarismo moderno a utilidade não é vista como prazer ou felicidade, mas sim como satisfação de um desejo. A grande crítica de Sen feita ao utilitarismo nas ambas facetas, clássico e ou moderno, é porque os dois são indiferentes às liberdades substantivas.

Na base informacional da utilidade é importante levar em consideração o bem-estar da cada pessoa e esse bem-estar é essencialmente mental. Sen (2015, p.84 e 85) destaca os requisitos da avaliação utilitarista, que são: o consequencialismo, julgar as escolhas apenas pelas suas consequências; o welfarismo que reduz a apreciação das situações ao que é útil nelas e por fim o somatório que agrega as utilidades de diferentes pessoas para o todo. Ao juntar-se o consequencialismo, o welfarismo e o somatório ter-se-ia a ideia de justiça e a injustiça seria a perda da utilidade.

Em análise ao utilitarismo, Sen (2015, p.86) afirma:

Embora os méritos do utilitarismo possam estar sujeitos a alguns questionamentos, essa visão tem insights consideráveis, em particular a importância de levar em consideração os resultados das disposições sociais ao julgá-los, (...) a necessidade de atentar para o bem-estar das pessoas envolvidas ao julgar as disposições sociais e seus resultados.

Ainda no tocante ao utilitarismo, Sen vislumbra como desvantagem o fato de a abordagem utilitarista não levar em consideração as desigualdades, assim como também não 
possui interesse pelos direitos, liberdades substantivas e ainda o condicionamento mental. É possível o vislumbre de pessoas com liberdades restringidas e mentalmente condicionado à determinada situação quando voltamos nossas atenções as pessoas que vivem no isoladas no campo e não possuem qualquer interesse por seus direitos civis e políticos.

Em continuidade à análise das perspectivas de justiça tratadas por Sen, o libertarismo, diferente da teoria utilitarista, não tem interesse direto na felicidade, nem tampouco na satisfação dos desejos, consistindo sua base informacional em liberdades formais e direitos de vários tipos.

Sen (2015, p.82 e 83) observa que as bases informacionais do utilitarismo e libertarismo no sentido de justiça são totalmente incompatíveis. Enquanto no utilitarismo temse como base informacional o prazer, a felicidade e a realização dos desejos; no libertarismo tem-se, como base informacional, a obediência às regras de liberdade formal e ações corretas. Ambas recebem duras críticas de Sen.

Outra abordagem das perspectivas da justiça, feita por Sen, é a teoria da justiça social de John Rawls, apontada como sendo uma das mais importantes teorias contemporâneas de justiça. Sua principal característica é a priorização da ordem política, obediência às leis e liberdades formais em detrimento de fatores sociais. Muito questionada por Sen $(2015$, p.91) onde aponta que o argumento em favor dessa total prioridade pode ser questionado demonstrando-se a força de outras considerações, como a das necessidades econômica, nesta perspectiva deve ser considerado restrito.

John Rawls estabelece que as pessoas têm de assumir a responsabilidade por suas escolhas, ao afirmar que duas pessoas recebem a mesma cesta de bens, porém um indivíduo por possuir gosto mais caro é menos "feliz" que o outro. Já Adam Smith destaca que coisas necessárias são os bens indispensáveis, necessários, mas também qualquer coisa que segundo o costume do país se torne indecente a pessoa viver sem.

Sandel (2014, p. 270) aponta que "a teoria de Rawls da prioridade ao que é certo sobre o que é bom e reflete a convicção de que uma pessoa moral é um sujeito com objetivos que ele próprio escolheu".

Na teoria do libertarismo, pensada por Robert Nozick, existe a prioridade total dos direitos e Sen destaca (2015, p.93):

A prioridade inflexível dos direitos libertários pode ser particularmente problemática, pois as consequências reais da operação desses intitulamentos 
podem incluir resultados terriveis. Em particular pode conduzir à violação da liberdade substantivas dos indivíduos para realizar as coisas às quais eles têm razão para atribuir enorme importância, como escapar à mortalidade evitável, ser bem nutrido e sadio e saber ler, escrever e contar. A importância dessas liberdades constitutivas não pode ser descartada com a justificativa da "prioridade da liberdade formal"

$\mathrm{Na}$ concepção de Sem, o libertarismo é limitado pois negligencia as liberdades substantivas dos indivíduos, propiciando total precedência aos direitos e liberdades formais. É necessário, portanto uma base informacional mais ampla. Os libertários também defendem o Estado neutro que respeite a escolha individual (SANDEL, 2014, p. 271).

Ele igualmente critica e aponta a limitação do utilitarismo, ao destacar que este analisa o bem-estar das pessoas pela renda real, não levando em consideração as diferenças e necessidades especiais de cada um, como idade, sexo, doenças, anseios. A diversidade dos seres humanos são muitas e é neste sentido que existe a dificuldade de designar esse bem-estar pelo recebimento de renda. Fazer comparações interpessoais é muito diferente de explicar o comportamento de escolha, e os dois só podem ser identificados mediante uma confusão conceitual (SEN, 2015, p. 97).

Dois indivíduos podem receber a mesma renda em valor, porém as necessidades de cada um podem variar conforme os anseios, por exemplo um indivíduo idoso, que possui doenças próprias da idade e uma pessoa jovem, saudável, em pleno gozo de suas atividades; mesmo aferindo a mesma renda não terão a mesma qualidade de vida.

Deve ser levado em consideração as questões sociais, ambientais, interpessoais, variações de clima social e a distribuição na família, as rendas reais podem ser indicadores muito insatisfatório dos componentes do bem-estar e da qualidade de vida que as pessoas têm razão para valorizar, destaca Sen (2015, p.111).

Michael Sandel (2014, p.271) aduz:

Sejam elas igualitárias sejam libertárias, as teorias da justiça que defendem a neutralidade tem um grande apelo. Elas mostram que é possível evitar que a política e a lei acabem por se enredar nas controvérsias morais e religiosas muito frequentes nas sociedades pluralistas. E expressam uma inovadora concepção da liberdade humana que nos transforma em autores das únicas obrigações morais que nos restringem. Ainda que atraente, no entanto, essa concepção de liberdade é falha. Assim como a aspiração de encontrar princípios de justiça que se mantenham neutros em relação às diferentes concepções da vida boa. 
Por fim, Amartya Sen encerra ao afirmar que as bases informacionais, acima mencionadas, possuem seus benefícios e suas limitações ao não levar em consideração as liberdades substantivas e a capacidade do indivíduo de levar a vida que deseja e valoriza.

\section{CONSIDERAÇÕES FINAIS}

Amartya Sen aponta como proposta um novo desenvolvimento pautado nas liberdades substantivas e capacidades dos indivíduos. Não há que se falar em desenvolvimento, apenas, como crescimento econômico, devendo-se ter como preocupação ademais a qualidade de vida da sociedade, o fortalecimento da democracia e a concretização das liberdades substantivas.

Fator de extrema importância é a diferenciação de modernização e desenvolvimento, podemos vislumbrar cidades extremamente modernas, possuidoras, porém, de periferia com grandes privações de liberdade, extrema pobreza, sem acesso à saúde e educação de qualidade, falta de saneamento básico, entre outras limitações. Não havendo modificação nas estruturas econômicas e sociais e tão somente na elevação de índices econômicos, dá-se, tão somente, um crescimento desarraigado de desenvolvimento.

Existem diversas privações de liberdade que afetam de maneira substancial o pleno desenvolvimento, privações destacadas por Sen como as fomes coletivas, o pouco acesso aos serviços de saúde, desigualdades entre homens e mulheres além de castração dos direitos políticos e civis; privações essas decorrente da escolha de processos errados.

Ademais, Amartya Sen demonstra três bases informacionais para os fundamentos da justiça, utilitarismo clássico e moderno, libertarismo e teoria da justiça de John Rawls, para ele todas elas possuem seus benefícios, porém são falhas por não levar em consideração as liberdades substantivas dos indivíduos.

\section{REFERENCIAS}

BENTHAM, Jeremy. An introduction to the principles of morals and legislation. Londres, reedição, Oxford, Clarendon Press, 1907.

BERCOVICI, Gilberto. Constituição Econômica e Desenvolvimento. Uma leitura a partir da Constituição de 1988. Malheiros. São Paulo, 2005.

COMPARATO, Fábio Konder. A afirmação histórica dos Direitos Humanos. São Paulo, Saraiva, 1999. 
FURTADO, Celso. Introdução ao desenvolvimento. Enfoque histórico-estrutural. Rio de Janeiro: Paz e Terra, 2000. 2000 .

Teoria e Política do Desenvolvimento Econômico. Rio de Janeiro: Paz e Terra,

RIVERO, Oswaldo de. O mito do desenvolvimento. Os países inviáveis no século XXI. Petrópolis: Editora Vozes, 2002.

VEIGA, José Eli da. Desenvolvimento Sustentável. Desafio do século XXI. Garamond. Rio de Janeiro, 2010.

SACHS, Ignacy. A terceira Margem. Em busca do ecodesenvolvimento. Garamond. São Paulo, 2007.

SANDEL, Michael J. Trad. de Heloisa Matias e Maria Alice Máximo. Justiça: o que é fazer a coisa certa. Rio de Janeiro. 15. ed. Civilização Brasileira, 2014.

SEN, Amartya. Desenvolvimento como liberdade. São Paulo: Companhia de Bolso, 2015. 